\title{
Wind-Induced Vibration Control of Dalian International Trade Mansion by Tuned Liquid Dampers
}

\author{
Hong-Nan Li, Ting-Hua Yi, Qin-Yang Jing, \\ Lin-Sheng Huo, and Guo-Xin Wang
}

Faculty of Infrastructure Engineering, Dalian University of Technology, Dalian 116023, China

Correspondence should be addressed to Ting-Hua Yi, yth@dlut.edu.cn

Received 29 May 2011; Accepted 30 June 2011

Academic Editor: Xue-Jun Xie

Copyright (C) 2012 Hong-Nan Li et al. This is an open access article distributed under the Creative Commons Attribution License, which permits unrestricted use, distribution, and reproduction in any medium, provided the original work is properly cited.

This paper focuses on the wind-induced vibration control of the Dalian international trade mansion (DITM) by using the tuned liquid dampers (TLDs). To avoid the intensive computationally demanding problem caused by tens of thousand of degrees of freedom (DOF) of the structure in the numerical analysis, the three-dimension finite element model of the DITM is first simplified to the equivalent series multi-DOF system. The wind loading is subsequently simulated by the Davenport model according to the structural environmental condition where the actual samples of wind speed are measured. Following that, the shallow- and deep-water wave theories are applied to model the liquid sloshing inside TLDs, the tank sizing, and required water depth, and numbers of TLDs are given according to the numerical results of different cases. Comparisons between uncontrolled and controlled displacement and acceleration responses of the DITM under wind forces show that the designed shallow tank has higher efficiency than the deep one, which can effectively reduce the structural response amplitudes and enhance the comfortableness of the mansion. The preliminary TLD design procedure presented in this paper could be applied as a reference to the analysis and design of the wind-induced vibration for high-rise buildings using the TLD.

\section{Introduction}

In recent years, the newly developed construction technologies toward lighter and stronger materials have facilitated the realization of more and more high-rise buildings in urban areas where space usage is demanding [1]. This kind of structures have, in general, low frequencies and damping ratios associated with their fundamental oscillation modes, and when subjected to dynamic loadings, they may experience large amplitudes of bending and torsional oscillation. Especially, if a high-rise building was built in a wind prone area, the 
building would experience large deflection due to mean wind and considerable vibration due to aerodynamic effects. Serious vibrations may cause fatigue damage in structural members, and thereby increasing the maintenance cost of the building. In addition, the excessive acceleration magnification will also frequently cause occupants' discomfort $[2,3]$.

The suppression of these oscillations has become one of the major concerns to civil engineers. A number of methods exist for improving the performance of existing structures to meet the requirements. Strengthening of the buildings or the installation of a base isolation system is complicated, difficult, and expensive. Therefore, incorporating control devices such as the active and passive tuned mass dampers (AMD and TMD) $[4,5]$, tuned liquid dampers (TLD) $[6,7]$, and tuned liquid column dampers (TLCD) $[8,9]$ have been proposed to mitigate excessive oscillations. Among many varieties of control devices, the TLD is a good candidate. A TLD consists of one or multiple rigid tanks, partially filled with a liquid (usually water), which is typically located near the top of a building. As the building moves in the severe wind or earthquake attack, the fluid contained within the tank begins to slosh. The fluid thereby absorbs vibrational energy from the structure and transforms it into kinetic and potential energy of the sloshing fluid. The sloshing energy is subsequently dissipated through the fluid's viscosity, or drag produced by flow dampening devices such as baffles, poles, nets or screens [10]. This kind of device is particularly well suited for tall buildings, since they usually contain water storage for potable or emergency use. With the already available water utilized and proper modifications to the existing storage tanks, a TLD can be formed without introducing an unnecessarily large additional mass and only require very low maintenance and operating cost. Furthermore, its natural frequency and damping characteristics can be modified easily by changing the geometry of the tank, the depth of the liquid layer, and the properties of the contained liquid [11].

Since TLD was first proposed by Bauer [12] for suppressing horizontal vibration of building structures, many experimental and numerical research studies were done over the past few years to illustrate the effectiveness of a TLD as a vibration-control device for structures subjected to both harmonic and broad-band excitations. Soong and Dargush proposed the use of a single TLD with a rectangular plan in control of vibration modes along orthogonal two directions [13]. Zhang et al. proposed a liquid damper that can reduce bidirectional response using crossed tube-like liquid container [14]. Tamura et al. reported vibration control effect of cylindrical TSDs obtained for both orthogonal axes of the building plan based on measurement of acceleration response [15]. Research [16] has been done to study the application of rectangular liquid dampers to reduce the vibration of multidegree of freedom structures. Multiple tuned liquid dampers, which consist of a number of tuned liquid dampers whose natural frequencies are distributed over a certain range around the fundamental natural frequency of the structure, were suggested Fujino et al. [17] who referred to the idea of multiple tuned mass dampers [18] for more effectively suppressing dynamic responses, because the modal frequency of structure is not uncertain in practice. Very recently, Samanta and Banerji [19] investigated a modified TLD configuration to improve the effectiveness of TLDs.

This paper presents a practical example for the effectiveness and feasibility of using TLDs on the Dalian international trade mansion (DITM), a super high-rise RC structure, to control wind-induced vibration. The preliminary design procedure for initial TLD sizing design for a high-rise building is summarized and outlined, which could be applied as a reference to the analysis and design of the wind-induced vibration for high-rise buildings using the TLDs. 


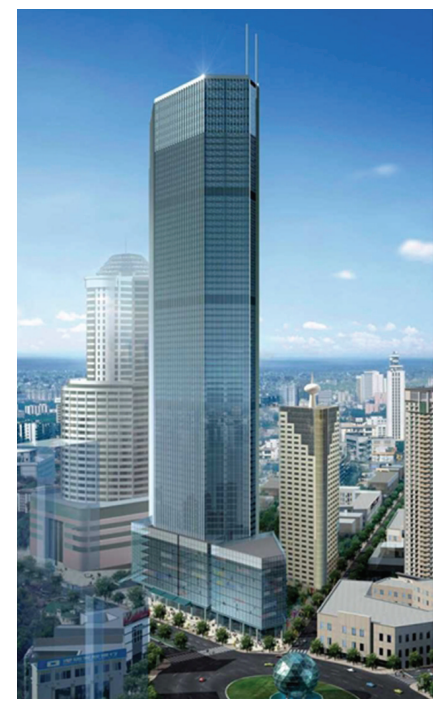

Figure 1: Dalian international trade mansion.

\section{Analytical Model}

\subsection{Mansion Outline}

The DITM is being built in the center of Dalian city of China, which is of 81 stories (including one-story basement) with the size of $339 \mathrm{~m}$ high and $77.7 \mathrm{~m}$ long in the east-west direction and $44 \mathrm{~m}$ wide in south-north direction. The total building area is $290,000.00 \mathrm{~m}^{2}$. The DITM is the highest building in the northeast of China (shown in Figure 1) [20]. Since the basic wind pressure in the Dalian region is $0.75 \mathrm{KN} / \mathrm{m}^{2}$ and the mansion is slender, that is, the ratio of height over width is 6.7 , it is relatively more flexible to large wind-vibration action in the horizontal direction. Consequently, the water tanks in the building will be designed as the turned liquid dampers to reduce its horizontal displacement and acceleration. Figure 2 shows the 3D finite element (FE) analytical model and the ichnography of the top story. The overall model has 34,308 node elements, 34,791 frame elements, and 29,071 shell elements, considering 36 section types and 11 materials' properties.

\subsection{Simplified Model}

As known, due to inherent nonlinear liquid damping, iteration is generally required in order to obtain the dynamic response of TLD-structure systems. It is no doubt that a solution scheme resorting to iteration requires a great deal of computational effort in searching for optimal parameters of dampers numerically. It would be quite a time-consuming task to carry out a detailed design of the damper. On the other hand, for a large-scale complicated structure like the DITM, whose three-dimension finite element (FE) model may have tens of thousand of DOFs, to facilitate design of the TLDs, a systematic and efficient approach is needed to solve such a computationally demanding problem. Considering that the structural stiffness of the structure in two horizontal directions is obviously different, it could mainly 


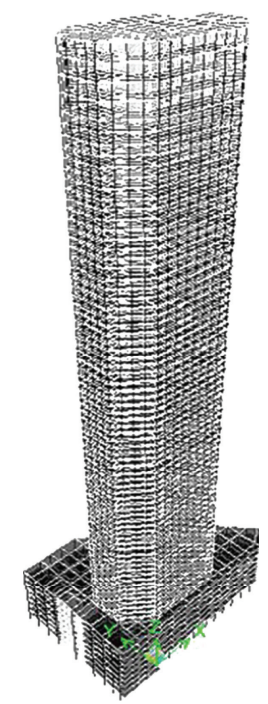

Figure 2: 3D finite element analytical model.

take into account the structural vibration reduction in the direction of weaker stiffness. Thus, the FE model of the DITM could be simplified as the bending-shear model with 81 degrees of freedom by the use of the approach called as the equivalent rigidity parameter identification method which given by Sun et al. [21].

The damping matrix of structure is expressed as the Rayleigh orthogonal damping formulation, and the damping ratio of the first two modes is chosen as $4 \%$. Here, the diagonal elements of mass, stiffness, and damping matrices are illustrated in Figure 3. The natural frequencies of the first two modes are obtained by the FE model of the original structure and simplified model, and their relative errors to compare the accuracy of two models are calculated by

$$
\frac{\left|T_{f}-T_{s}\right|}{T_{f}} \times 100 \%
$$

where $T_{f}$ and $T_{s}$ is the periods of finite element model and simplified model, respectively.

The results are listed in Table 1. And the comparisons of first two modes of two models are shown in Figure 4. As known, a TLD generally need to be designed to operate at or near the resonant frequency of the structure in order to maximize the absorbed and dissipated energy, and thus maximize the benefit of the TLD. It can be seen from Table 1 and Figure 4 that the errors of computational results of the two models are quite small so that the simplified model can be applied to calculate the vibration responses of original structure to environmental loadings. 


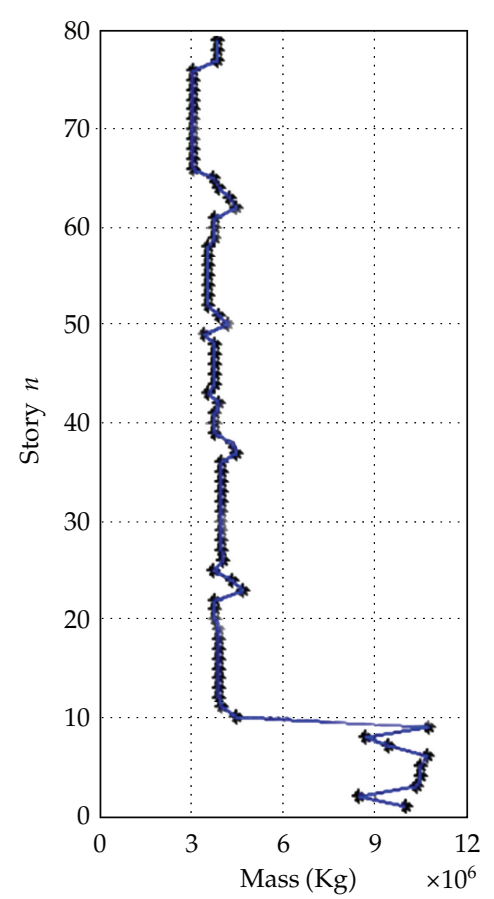

(a)

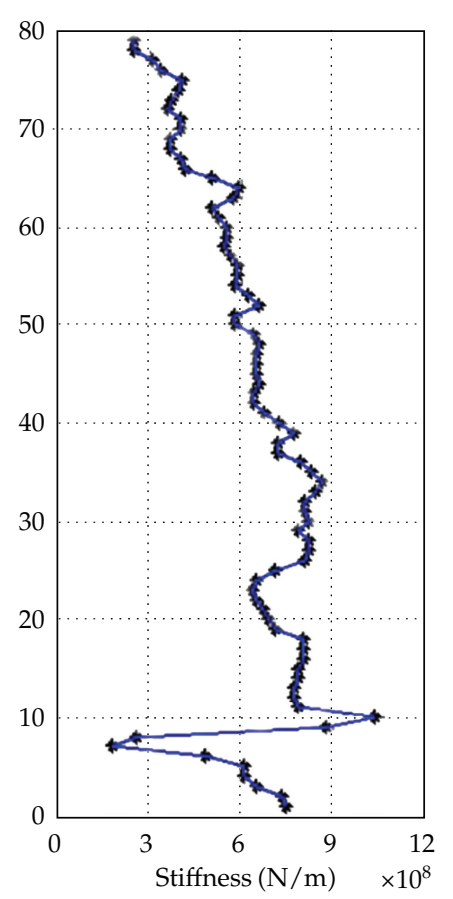

(b)

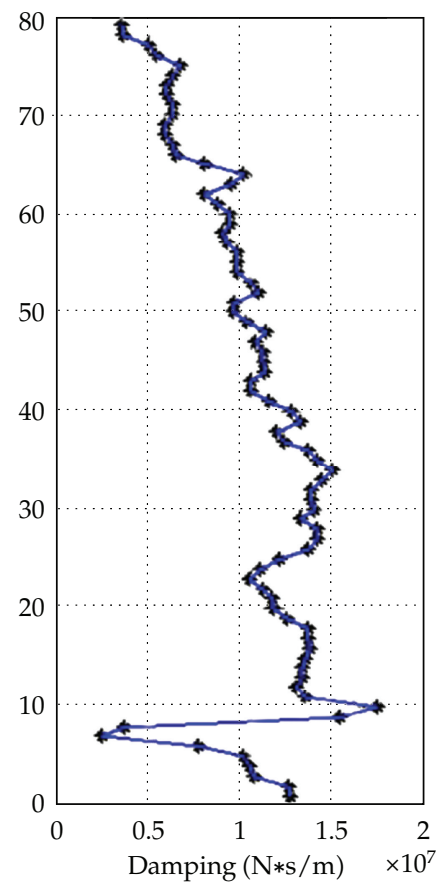

(c)

Figure 3: Diagonal elements in mass, stiffness, and damping matrixes of structural model.

Table 1: Comparison of relative errors of periods of two models.

\begin{tabular}{lccc}
\hline Mode & Finite element model & Simplified model & Relative error \\
\hline 1st period/s & 6.636 & 6.768 & $1.99 \%$ \\
2nd period/s & 1.526 & 1.522 & $0.27 \%$ \\
\hline
\end{tabular}

\section{Wind Load}

\subsection{Pulse Wind Load Simulation}

In wind engineering, the unitary wind pressure spectrum, suggested by Zhang [22], is the most popularly used one that has the same spectrum value in height

$$
S_{f}(f)=\frac{2 x^{2}}{3 f\left(1+x^{2}\right)^{4 / 3}}, \quad x=1200 \frac{f}{\bar{V}_{10}},
$$

where $\bar{V}_{10}$ represents the mean wind velocity on the height of 10 meters $(\mathrm{m} / \mathrm{s}), f$ is the pulse frequency $(\mathrm{Hz})$. 


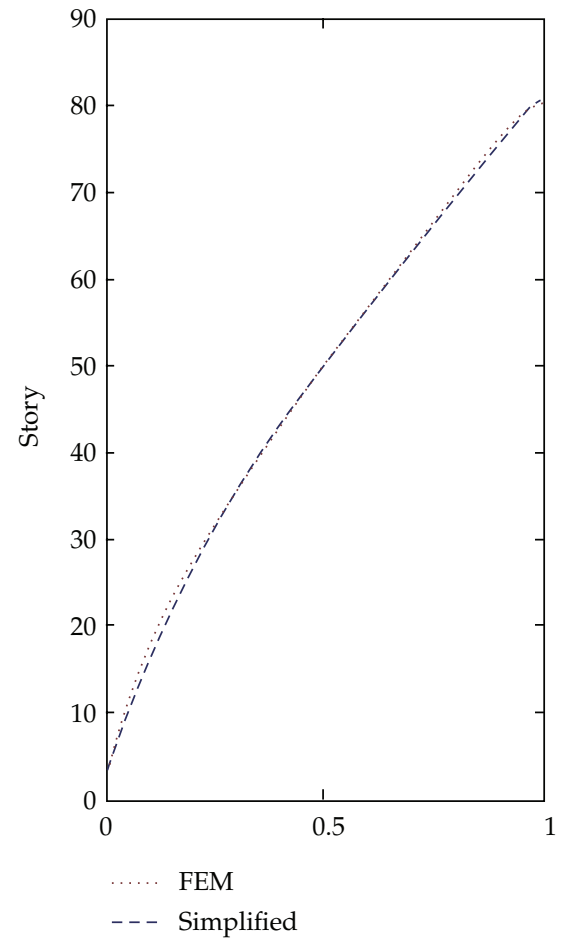

(a) 1st mode

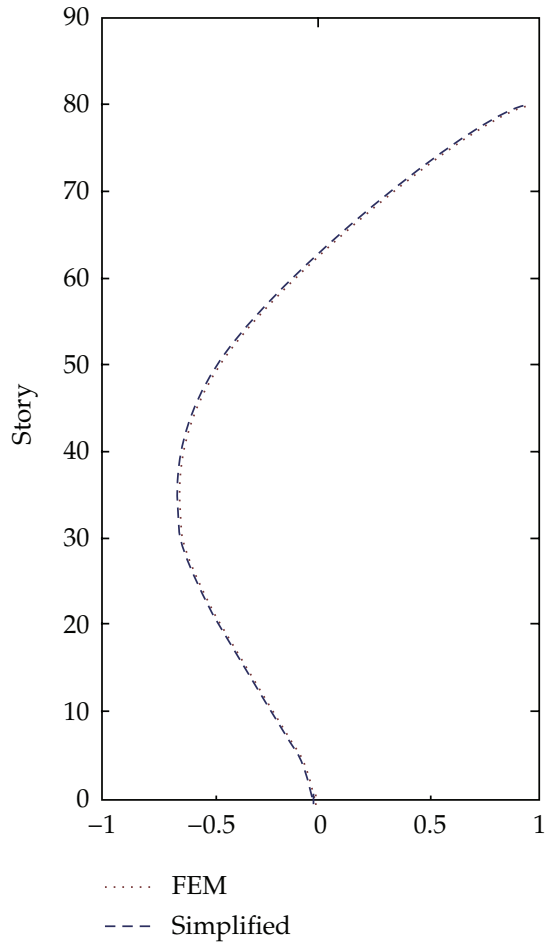

(b) 2nd mode

Figure 4: Diagrams of the 1st and 2nd mode comparison of two models.

Considering one-dimensional random process $\{f(t)\}$ with $n$ variables and zero-mean value, that is, $f_{1}(t), f_{2}(t), f_{3}(t), \ldots, f_{n}(t)$, their power spectrum density function could be expressed as [23]:

$$
S_{F_{i j}^{*}}(w)=\left[S_{p}\right] S_{f}(w), \quad i, j=1,2,3, \ldots, n,
$$

in which

$$
\left(S_{p}\right)_{k h}=p_{k h} P_{k} P_{h}
$$

where $P_{k}=\mu_{f}\left(Z_{k}\right) \mu_{D}\left(Z_{k}\right) \mu_{Z}\left(Z_{k}\right) \mu_{r} w_{0} \Delta A_{k} / \mu$, in which $\mu_{f}, \mu_{D}$, and $\mu_{Z}$ means the pulse coefficient at the $k$ th story, shape coefficient, and varying coefficient of wind pressure along height, $\mu_{r}$ and $\mu$ are the reoccurrence period coefficient and wind factor, $w_{0}$ and $\Delta A_{k}$ represent the basic wind pressure and area of suffering wind at the $k$ th story, and $p_{k h}=$ $\exp \left(-\left|Z_{k}-Z_{h}\right| / 60\right)$ implies the vertical coherence factor of pulse wind.

Based on the Shinozuka theory [24], the random process $\{f(t)\}$ may be simulated by the following equation:

$$
f_{j}(t)=\sqrt{2 \Delta \omega} \sum_{m=1}^{j} \sum_{l=1}^{n}\left|H_{j m}\left(\omega_{m l}\right)\right| \cos \left(\omega_{m l} t-\theta_{j m}\left(\omega_{m l}\right)+\phi_{m l}\right), \quad j=0,1,2,3, \ldots, n,
$$


where $j$ is the maximum positive integer, $\Delta \omega$ means the frequency increment calculated by $\Delta \omega=\left(\omega_{b}-\omega_{a}\right) / N$ in which $\omega_{a}$ and $\omega_{b}$ are the starting and ending frequency, $\phi_{m l}$ denotes the random phase distributed in the range of $(0,2 \pi), H_{j m}\left(\omega_{m l}\right)$ implies the element in the matrix, $\mathbf{H}(\omega)$ and $\mathbf{H}(\omega)$ is the Cholesky decomposition of matrix $\mathbf{S}(\omega)$; that is,

$$
\mathbf{S}(\omega)=\mathbf{H}(\omega) \mathbf{H}^{*}(\omega)^{T}
$$

in which, $\omega_{m l}=(l-1) \Delta \omega+\left(\frac{m}{n}\right) \Delta \omega, \theta_{j m}\left(\omega_{l}\right)$ is given by

$$
\theta_{j m}\left(\omega_{l}\right)=\tan ^{-1}\left(\frac{\operatorname{Im}\left\lfloor H_{j m}\left(\omega_{l}\right)\right\rfloor}{\operatorname{Re}\left[H_{j m}\left(\omega_{l}\right)\right]}\right)
$$

Based on the central limitation theorem, the random process $\left\{f_{j}(t)\right\}$ will gradually tend to be the Gauss process as $N \rightarrow \infty$. And the time interval $\Delta t$ should meet the requirement of $\Delta t \leq 2 \pi / 2 \omega_{b}$ in order to avoid the sample superposition according to the sampling theory.

As mentioned above, the good samples can be acquired from (3.4) only if $\mathbf{S}(\omega)$ is known, and $N, \omega_{b}$ and $\Delta t$ are properly selected. However, since this method would consume more time and energy while calculating, the Fast Fourier Transform algorithm (FFT) is introduced in (3.4) to obtain higher efficiency:

$$
\begin{aligned}
& f_{j}(p \Delta t)=\operatorname{Re}\left\{\sum_{m=1}^{j} h_{j m}(q \Delta t) \exp \left[i\left(\frac{m \Delta \omega}{n}\right)(p \Delta t)\right]\right\}, \\
& p=0,1,2,3,4, \ldots, 2 N \times n-1 ; \quad j=0,1,2,3,4, \ldots, n,
\end{aligned}
$$

where

$$
h_{j m}(q \Delta t)=\sum_{l=0}^{2 N-1} g_{j m}(l \Delta \omega) \exp \left[i \frac{\pi d q}{N}\right], \quad q=0,1,2,3,4, \ldots, n-1
$$

in which

$$
g_{j m}(l \Delta \omega)= \begin{cases}\sqrt{2 \Delta \omega} H_{j m}\left(l \Delta \omega+\frac{m \Delta \omega}{n}\right) \exp \left(i \phi_{m l}\right), & 0 \leq l<N \\ 0, & N \leq l<2 N .\end{cases}
$$

It can be known from (3.8) and (3.9) that $h_{j m}(q \Delta t)$ is the inverse Fourier transform of $g_{j m}(l \Delta \omega)$, which is calculated by FFT. Thus, 81 samples of wind load are calculated by selecting $N=8192, \Delta t=0.05, \omega_{a}=0$, and $\omega_{b}=60$. The wind pressure time history of these samples acting on the top of structure is illustrated in Figure 5 and its theoretical and simulated spectra are shown in Figure 6. It can be seen from these figures that the simulated results are perfect. 


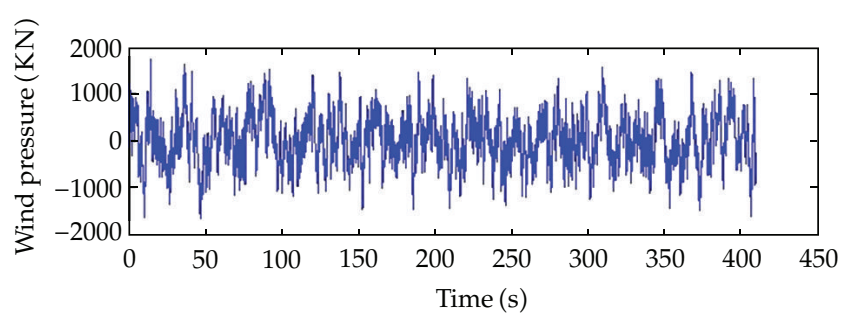

Figure 5: Wind load time history on top of building.

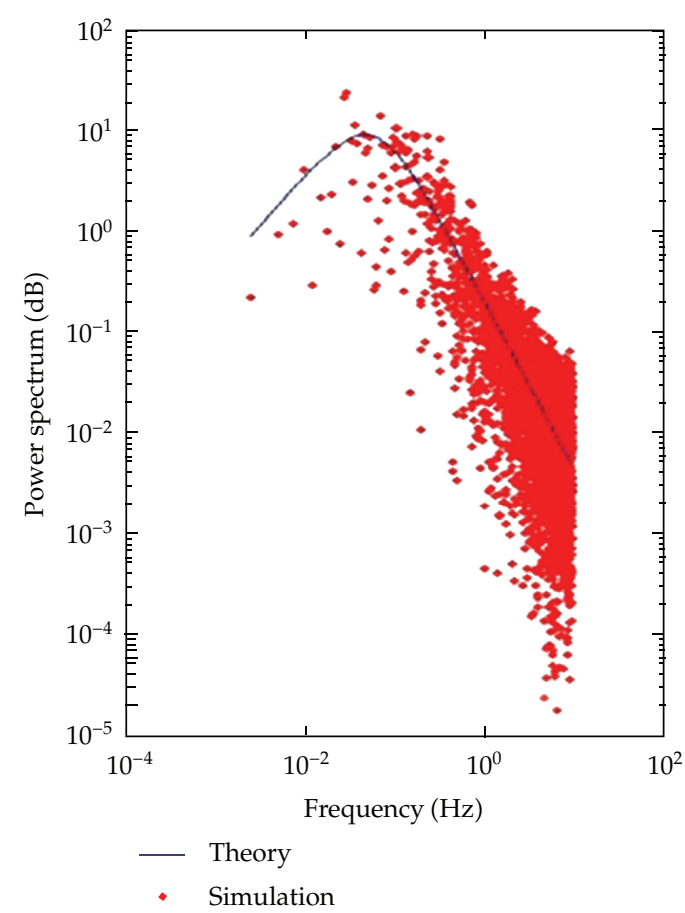

(a) Self-power spectrum of 81 st story

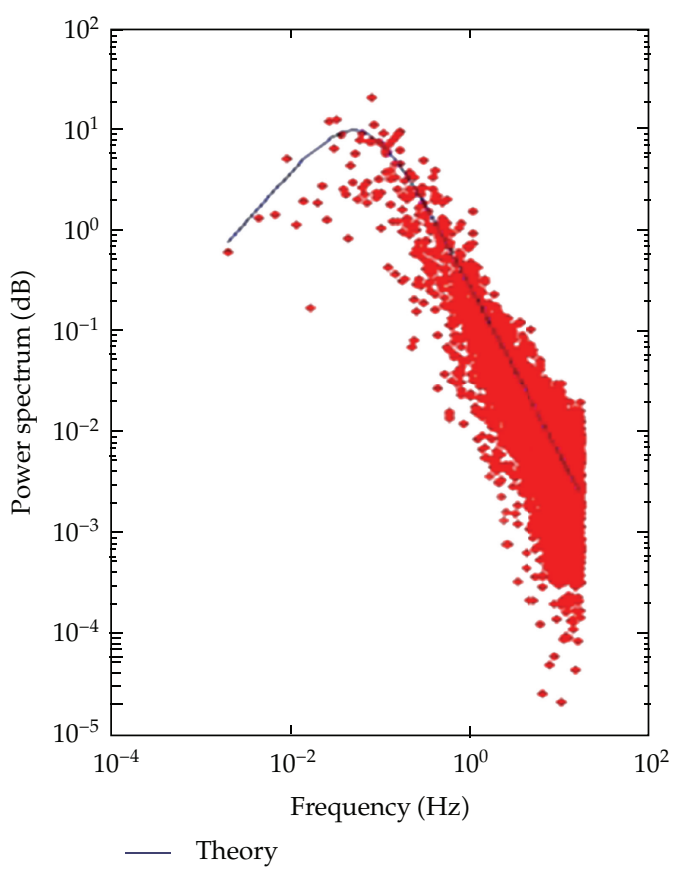

- Simulation

(b) Co-power spectrum of 81 st and 50th stories

Figure 6: Power spectral comparison between simulated and theoretical wind samples.

To verify if the simulated wind load may represent the actual wind action, the wind velocity time histories on the top of the nearby high-rise building ( $200 \mathrm{~m}$ in height) were measured by the smart ZDR-1F mode wind velocity instrument (Figure 7), the accuracy of which is as high as $\pm(0.5+0.05 *$ wind velocity $) \mathrm{m} / \mathrm{s}$, the measuring range $1.5 \sim 40 \mathrm{~m} / \mathrm{s}$, recognizing capability rate $0.1 \mathrm{~mm}$, recording interval range from 2 second to 24 hours $(2 \mathrm{~s}$ adopted in the measurement) [25]. The working diagram is illustrated in Figure 8. The measured results give the idea that the average velocity of these strong and stable samples is about $15.36 \mathrm{~m} / \mathrm{s}$, and Figure 9 is the wind velocity time history. 


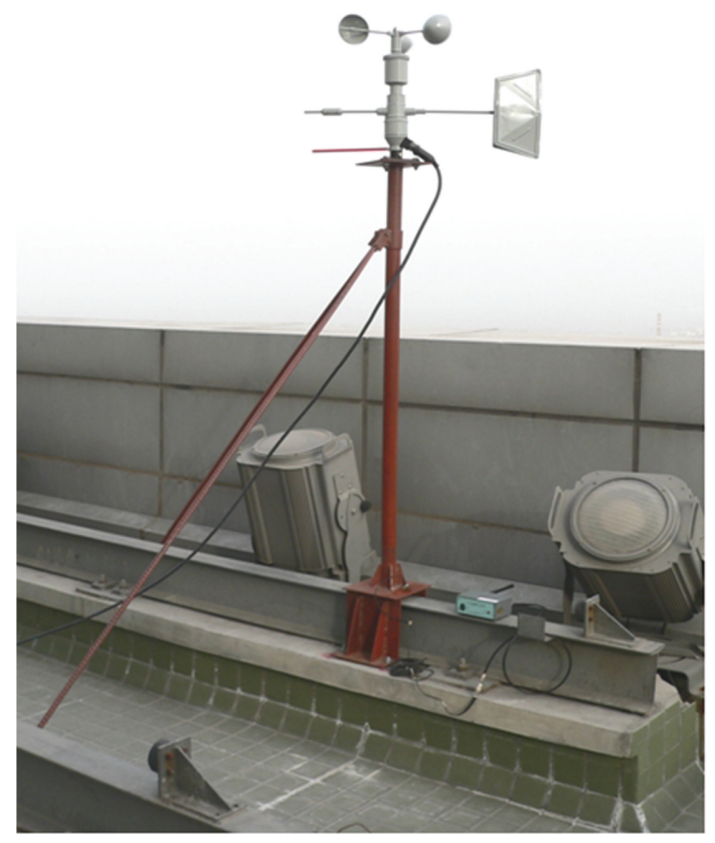

Figure 7: ZDR-1F-type wind velocity instrument.

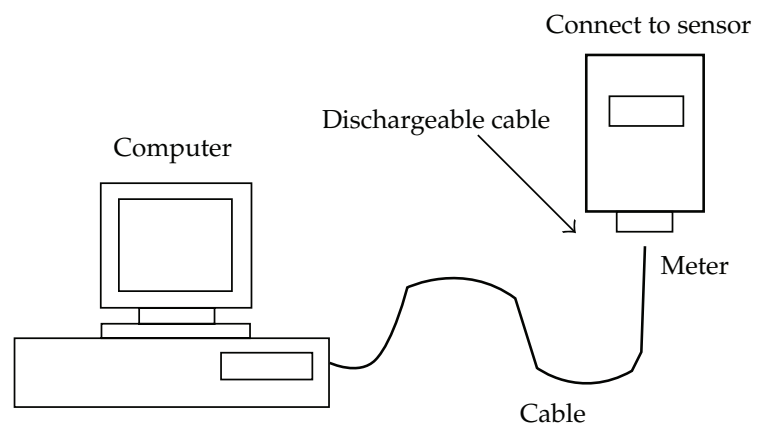

Figure 8: Working diagram.

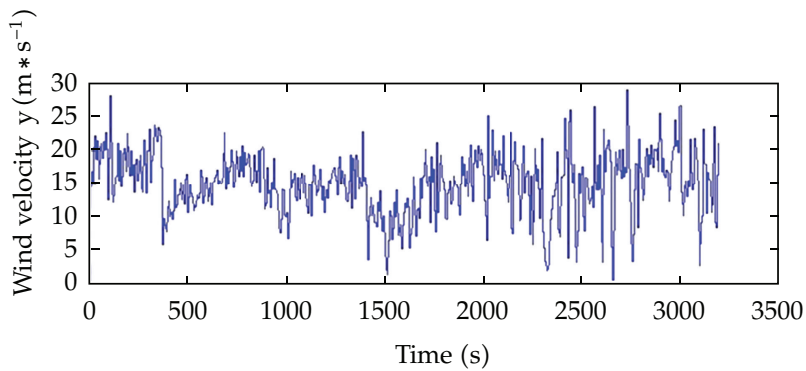

Figure 9: Recorded wind velocity time history. 


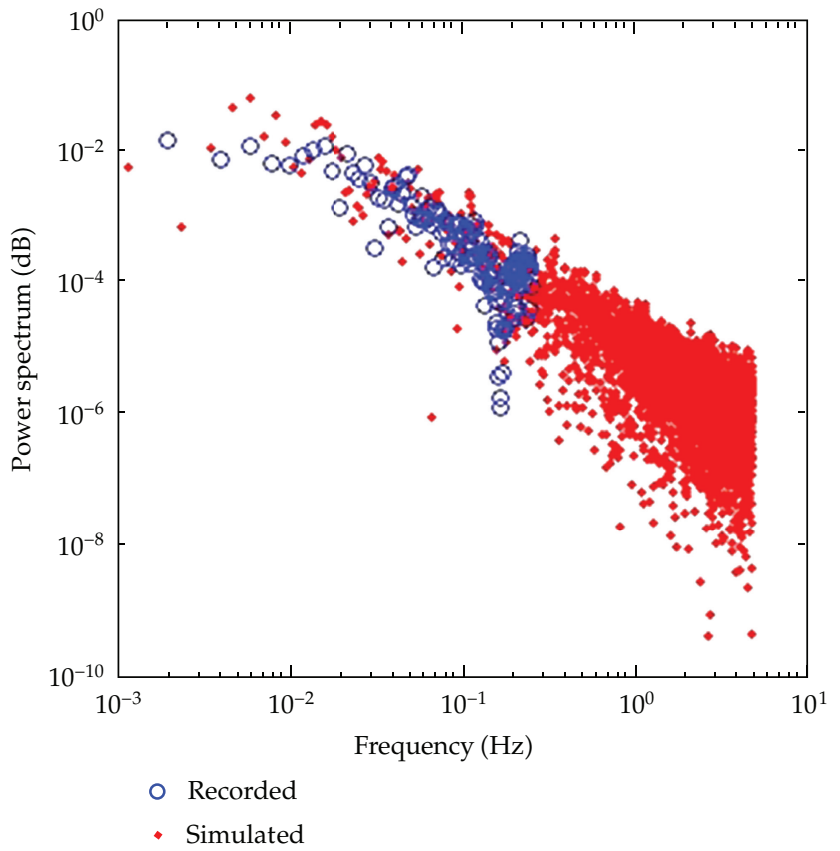

Figure 10: Spectral comparisons between simulated and recorded wind loads.

\subsection{Comparisons between Simulated and Actual Measured Wind Loads}

The spectral comparison between simulated and recorded wind loads is depicted in Figure 10. It is known from Figure 10 that they agree well each other, which indicates the fact that the simulated wind load is enough to represent the actual state and can be applied in the structural design and analysis.

\section{TLD Principle and Design}

\subsection{TLD Working Principle}

The TLD system may be a rectangle or circle tank fixed on the top of the building and may be one large tank or composed of some small tanks, in which the liquid in the tank may be deep or shallow. The TLDs will shake together with the building when suffering from wind load. The dynamic liquid pressure of generating surface wave acting on tank walls will reduce structural vibration. Usually, the TLDs are divided into two categories based on the ratio of liquid depth to the size in shaking direction inside the tank: the TLD of deep liquid if the ratio is larger than $1 / 8$, otherwise, the TLD of shallow liquid. The damping is due to energy dissipation through the internal fluid viscous forces and wave breaking (shallowliquid dampers). In the case of deep-liquid dampers, damping depends on the amplitude of liquid motion and on viscous forces. 


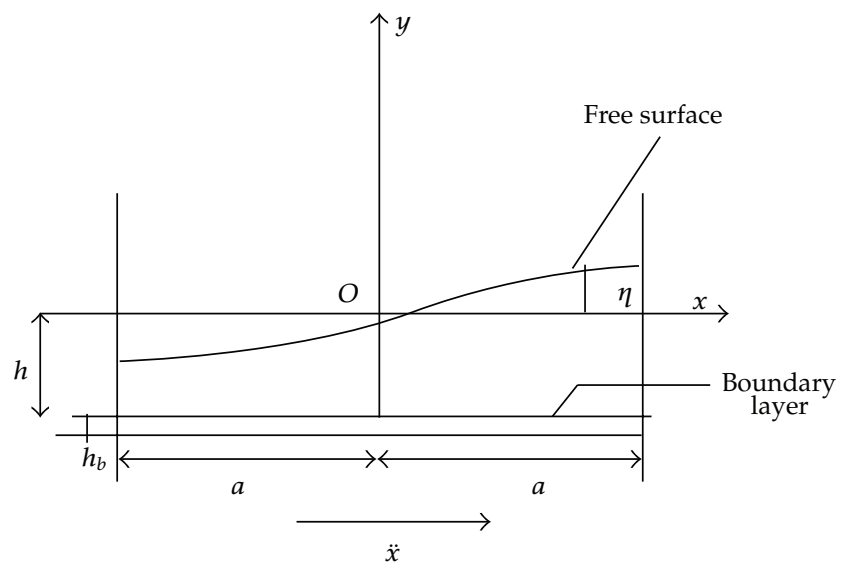

Figure 11: Diagram of liquid movement in TLD.

\subsection{Shallow Liquid Theory}

The following basic assumptions in deriving the equations of motion are adopted:

(1) the liquid in the TLDs vibrates in two dimensions,

(2) the liquid in the TLDs is incompressible and gyrating-free current,

(3) the pressure on liquid free surface is invariable,

(4) the friction may be produced only near boundary layers and on solid surface.

The liquid in TLDs may be divided into two parts according to the shallow wave theory, boundary layer and outside boundary layer, as shown in Figure 11. The dynamic viscous damping is generated mainly by liquid inner friction in the boundary layer due to small liquid damping in outside of boundary layer, so the basic equation of motion of liquid in two-dimensional TLDs may be described by continuous equations and Navier-Stokes equation inside and outside boundary layer [26]

$$
\begin{gathered}
\frac{\partial u}{\partial x}+\frac{\partial u}{\partial z}=0 \\
\frac{\partial u}{\partial t}+u \frac{\partial u}{\partial x}+w \frac{\partial u}{\partial z}=-\frac{1}{\rho} \frac{\partial p}{\partial x}-\ddot{x}_{g} \quad\left(-\left(h-h_{b}\right) \leq z \leq \eta\right) \\
\frac{\partial w}{\partial t}+u \frac{\partial w}{\partial x}+w \frac{\partial w}{\partial z}=-\frac{1}{\rho} \frac{\partial p}{\partial z}-g \quad\left(-\left(h-h_{b}\right) \leq z \leq \eta\right) .
\end{gathered}
$$

The equation of motion inside boundary layer is

$$
\begin{gathered}
\frac{\partial u}{\partial t}+u \frac{\partial u}{\partial x}+w \frac{\partial u}{\partial z}=-\frac{1}{\rho} \frac{\partial p}{\partial x}+v\left(\frac{\partial^{2} u}{\partial x^{2}}+\frac{\partial^{2} u}{\partial z^{2}}\right)-\ddot{x}_{g} \quad\left(-h \leq z \leq\left(h-h_{b}\right)\right), \\
\frac{1}{\rho} \frac{\partial p}{\partial z}=-g \quad\left(-h \leq z \leq\left(h-h_{b}\right)\right)
\end{gathered}
$$


where $u$ and $w$ are the velocities of liquid mass in $x$ and $z$ directions, $p$ means the liquid inner pressure, $h_{b}$ denotes the thickness of boundary layer, $\rho$ implies the liquid density, $v$ liquid dynamic viscosity factor, $\ddot{x}_{g}$ represents the acceleration of tank movement, and $g$ is the gravity acceleration.

The boundary conditions are

$$
\begin{array}{ll}
u=0, & (x= \pm a), \\
w=0, & (z=-h), \\
w=\frac{\partial \eta}{\partial t}+u \frac{\partial \eta}{\partial x}, & (z=\eta), \\
p=p_{0}=\text { const, } & (z=\eta) .
\end{array}
$$

The liquid movement outside the boundary layer is treated as potential flow, velocity potential function, $\Phi$, of which could be supposed as follows:

$$
\Phi(x, z, t)=F(x, t) \cosh [k(h+z)] .
$$

It is derived from potential function that

$$
\begin{aligned}
& u=\frac{\partial \Phi}{\partial x}=\frac{\partial F}{\partial x} \cosh (k(h+z)) \\
& w=\frac{\partial \Phi}{\partial z}=k F \sinh (k(h+z)) .
\end{aligned}
$$

Substituting (4.5) into (4.1) and (4.2), the basic equations are obtained after conversing by combing boundary condition(4.3)

$$
\begin{gathered}
\frac{\partial \eta}{\partial t}+h \sigma \frac{\partial(\phi u(\eta))}{\partial x}=0 \\
\frac{\partial}{\partial t} u(\eta)+\left(1-T_{H}^{2}\right) u(\eta) \frac{\partial}{\partial x} u(\eta)+g \frac{\partial \eta}{\partial x}+g h \sigma \phi \frac{\partial^{2} \eta}{\partial x^{2}} \frac{\partial \eta}{\partial x}=-\lambda u(\eta)-\ddot{x}_{S}
\end{gathered}
$$

where

$$
\begin{gathered}
\sigma=\frac{\tanh (k h)}{k h}, \\
\phi=\frac{\tanh (k(h+\eta))}{\tanh (k h)}, \\
T_{H}=\tanh [k(h+\eta)], \\
\lambda=\left(\frac{1}{n+h}\right) \frac{8}{3 \pi} \sqrt{\omega v}\left(1+\left(\frac{2 h}{b}\right)+S\right),
\end{gathered}
$$


which could be called as viscous coefficient. in which $k$ is the wave number taken as $\pi / 2$, $b$ means the tank width and $S$ implies the viscous influencing factor on the liquid surface usually taken as $0 \sim 2$.

To make each parameter dimensionless, it is expressed as

$$
x^{\prime}=\frac{x}{a}, \quad z^{\prime}=\frac{z}{h^{\prime}}, \quad \eta^{\prime}=\frac{\eta}{h^{\prime}}, \quad \varepsilon=\frac{h}{a}, \quad u^{\prime}=\frac{u}{C_{0}}, \quad t^{\prime}=\frac{t}{t_{0}}, \quad k^{\prime}=k a, \quad \ddot{x}_{S}^{\prime}=\frac{t_{0}^{2}}{a} \ddot{x}_{S},
$$

in which, $C_{0}=\sqrt{g h}, t_{0}=a / C_{0}$.

Equations (4.6) are discredited along the vibration direction of tank as follows:

$$
\begin{gathered}
\frac{d \eta_{i}^{\prime}}{d t^{\prime}}=\frac{\sigma}{\Delta x^{\prime}}\left(\phi_{i} u_{i}^{\prime}-\phi_{i+1} u_{i+1}^{\prime}\right) \quad(i=1 \sim n-1), \\
\frac{d \eta_{0}^{\prime}}{d t^{\prime}}=-\frac{2 \sigma}{\Delta x^{\prime}} \phi_{1} u_{1}^{\prime}, \\
\frac{d \eta_{n}^{\prime}}{d t^{\prime}}=\frac{2 \sigma}{\Delta x^{\prime}} \phi_{n} u_{n}^{\prime}, \\
\frac{d u^{\prime}}{d t^{\prime}}=\frac{1}{\Delta x^{\prime}}\left(\eta_{i-1}^{\prime}-\eta_{i}^{\prime}+H_{i}\left(K_{i-1}-K_{i}\right)+C_{i}\left(I_{i-1}-I_{i}\right)\right)-\lambda_{i}^{\prime} u_{i}^{\prime}-\ddot{x}_{S}^{\prime} \quad(i=1 \sim n),
\end{gathered}
$$

where

$$
\begin{gathered}
\Delta x^{\prime}=\frac{2}{n^{\prime}} \\
\phi_{i}=\frac{\tanh \left(k^{\prime} \varepsilon\left(1+\left(\eta_{i-1}^{\prime}+\eta_{i}^{\prime}\right) / 2\right)\right)}{\tanh \left(k^{\prime} \varepsilon\right)} \quad(i=1 \sim n), \\
H_{i}=\frac{\left(1-\left(\phi_{i} \tanh \left(k^{\prime} \varepsilon\right)\right)^{2}\right)}{2} \quad(i=1 \sim n), \\
I_{i}=\frac{\left(\left(\left(\eta_{i+1}^{\prime}-\eta_{i-1}^{\prime}\right) /\left(2 \Delta x^{\prime}\right)\right)^{2}\right)}{2} \quad(i=1 \sim n-1), \\
\left.\lambda^{\prime}=\frac{\left(u_{i}^{\prime}+u_{i+1}^{\prime}\right)}{2}\right)^{2} \quad(i=1 \sim n-1), \\
1+\left(\eta_{i-1}^{\prime}+\eta_{i}^{\prime}\right) / 2 \frac{8}{3 \pi \varepsilon C_{0}} \sqrt{\omega v}\left(1+\left(\frac{2 h}{b}\right)+S\right) .
\end{gathered}
$$


It is suggested here that the $n$ value may be taken as

$$
n=\frac{\pi}{(2 \arccos (\sqrt{(\tanh (\pi \varepsilon)) /(2 \tanh (\pi \varepsilon / 2))})}
$$

and then dynamic liquid pressure can be expressed as follows:

$$
F_{\mathrm{TLD}}=\frac{1}{4} M_{W} \frac{g h}{a}\left(\left(\eta_{n}^{\prime}+1\right)^{2}-\left(\eta_{0}^{\prime}+1\right)^{2}\right)
$$

where $M_{W}=2 p a b h$ represents liquid weight in the TLD.

\subsection{TLD Design}

It is known that the average participating factor of the 1st mode in structural displacement response is about $92.07 \%$ and the 2 nd mode is $6.67 \%$ by calculations. The two modal participating coefficients in the structural response are illustrated in Figure 12.

As mentioned above, the only first mode response is controlled by the TLDs in design, since it dominates the total structural response in the tall building. Then, the 1st oscillation frequency of liquid in TLDs is tuned to the first modal frequency of structure according to the TLD tuning condition; that is,

$$
\omega_{1}=\sqrt{\frac{\pi g}{2 a} \tanh \left(\frac{\pi h}{2 a}\right)}=0.92836
$$

Thus, the sizes of the TLDs, including the length $(R)$ and depth $(H)$, are designed as listed in Table 2.

\section{Calculation of Wind-Induced Structural Vibration Reduction}

\subsection{Equation of DITM for Structure-TLDs System}

The equation of motion for the structure-TLDs system is

$$
[M]\{\ddot{x}\}+[C]\{\dot{x}\}+[K]\{x\}=\{f(t)\}-[H]\left\{F_{\mathrm{TLD}}\right\},
$$

where $\{x\},\{\dot{x}\}$, and $\{\ddot{x}\}$ represent the structural displacement, velocity, and acceleration vectors, $[M],[C]$, and $[K]$ imply the structural mass, damping, and rigid matrices, $\{f(t)\}$ denotes the pulse wind load vector acting on structure, $\left\{F_{\mathrm{TLD}}\right\}$ means the control force vector of TLDs, and $[H]$ is the position matrix of TLDs in which its ith column vector $\{H\}_{i}=\left[\begin{array}{llllll}0 & \cdots & 0 & 1 & 0 & \cdots\end{array}\right]_{1 \times n}^{T}(1$ is in $j$ th column $)$ is that the $i$ th group TLDs are installed on the $j$ th story. 


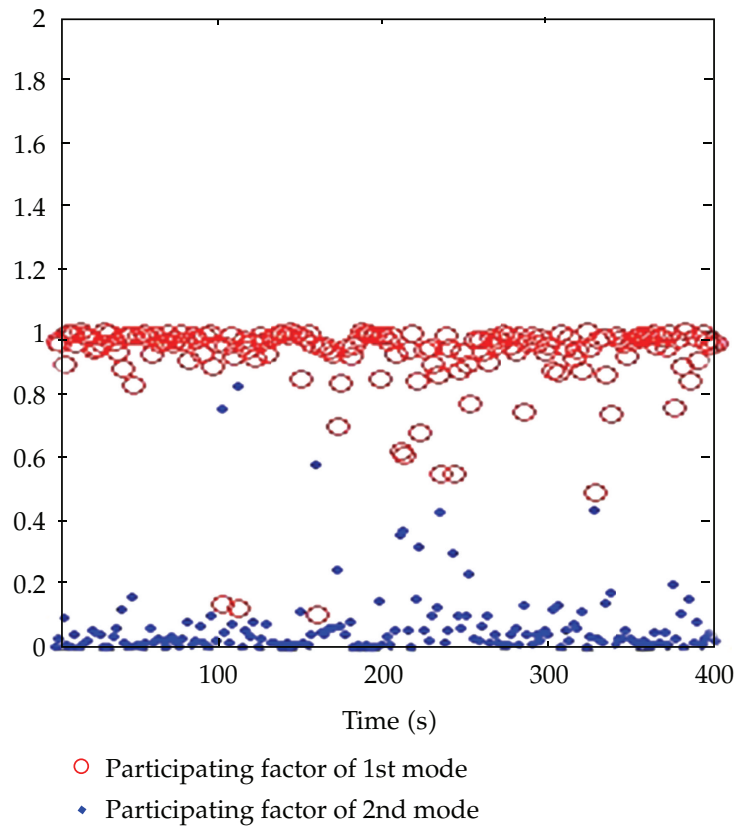

Figure 12: Participating factors of first two modes participant.

Table 2: Design sizes of TLDs.

\begin{tabular}{lccccccc}
\hline Length $/ 2 a$ & Width $/ B$ & $\begin{array}{c}\text { Liquid } \\
\text { depth/H }\end{array}$ & Height & $\begin{array}{c}\text { Total } \\
\text { weight }\end{array}$ & Number $/ n$ & $\begin{array}{c}\text { Liquid } \\
\text { depth ratio }\end{array}$ & Note \\
\hline $8.7605 \mathrm{~m}$ & $7.47 \mathrm{~m}$ & $0.7 \mathrm{~m}$ & $1.4 \mathrm{~m}$ & $3666 \mathrm{t}$ & 80 & 0.08 & $\begin{array}{c}\text { Overlapping } \\
\text { with } \\
4 \text { layer }\end{array}$ \\
\hline
\end{tabular}

\subsection{Effectiveness of Vibration Reduction}

In design, the TLDs are placed on the top story of building. Combining (5.1) with (4.9) and (4.12), the structural dynamic response is calculated by the subprogram, ode23 in MATLAB package, to obtain the vibration-reducing rates, $R e$, as

$$
\operatorname{Re}=\frac{r_{1}-r_{2}}{r_{1}} \times 100 \%,
$$

where $r_{1}$ and $r_{2}$ are the displacements (or peak accelerations) on the top story without and with TLD control, respectively.

The reduced displacement and acceleration amplitudes by installing the shallow liquid TLD are shown in Table 3.

Figure 13 shows the wave amplitude and time history of liquid oscillation force in the right side of liquid tank. Figures 14 and 15 typically depict the time histories of displacement and acceleration on the top story of structure. It is clear to know from Table 3 and Figures 13 15 that the structural responses can be reduced to different grades by TLDs, and wave amplitude curves indicate that the liquid oscillation is obviously nonlinear, which causes 
Table 3: Vibration-reducing rates of displacement and peak acceleration.

\begin{tabular}{lcccc}
\hline Case & Displacement $(\mathrm{cm})$ & Acceleration $\left(\mathrm{cm} \cdot \mathrm{s}^{-2}\right)$ & \multicolumn{2}{c}{ Vibration reducing rate $(\%)$} \\
Displacement & Acceleration \\
\hline Without control & 16.00 & 24.09 & & \\
With control & 13.27 & 18.33 & 17.06 & 23.856 \\
\hline
\end{tabular}

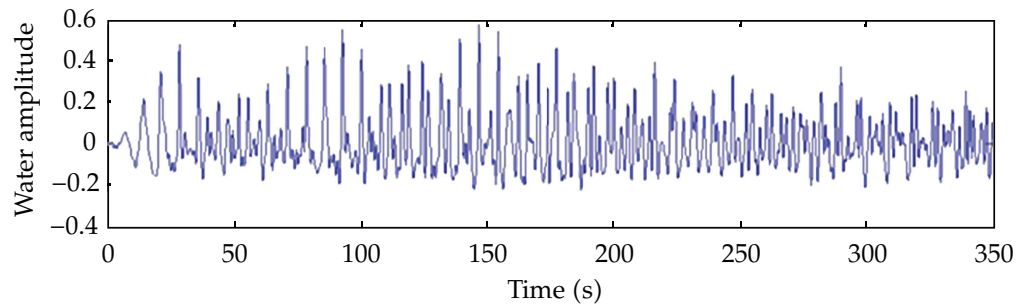

(a)

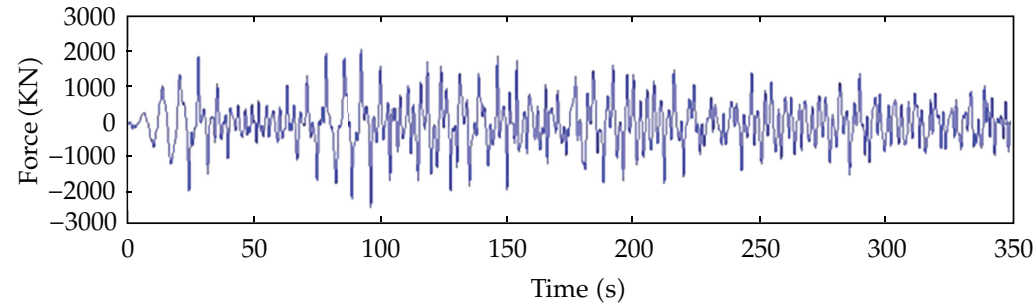

(b)

Figure 13: Wave amplitude and water oscillation force in right side of TLD.

partial amplifications in time histories of displacement and acceleration, and the liquid oscillation frequencies corresponding to these amplifications quickly vary. In general, the vibration-reducing effectiveness is very well and ideal and may meet the requirement for the design of wind-induced vibration of DITM.

\subsection{Comparison with TLD Design of Deep Liquid Theory}

The basic assumption of the deep liquid theory is that the liquid wave in TLDs is low and slow and its velocity potential function $\Phi=\Phi(x, y, z, t)$ can be deducted by solving basic equations with boundary conditions. According to the linear Bernoulli equation, the dynamic liquid pressure at any position in a rectangular TLD can be achieved. Thus, the force acting on structure will be the resultant force of dynamic liquid pressure on both left and right sides of rectangular TLDs, that is, [26]

$$
\begin{aligned}
F_{\mathrm{TLD}} & =-\int_{-H}^{0} B p_{j}(0, z, t) d z+\int_{-H}^{0} B p_{j}(R, z, t) d z \\
& =-\rho R B H\left[\ddot{x}_{T}(t)+\sum_{n=1,3, \ldots}^{\infty} \ddot{\omega}_{n}(t) \frac{2 b_{n}}{n \pi H} \tanh \frac{n \pi H}{R}\right],
\end{aligned}
$$

where $H, B$, and $R$ are the liquid depth, width, and length of fluid tank, $p_{j}(0, z, t)$ and $p_{j}(R, z, t)$ represent the dynamic liquid pressure acting on both left and right sides, $\rho$ is the 


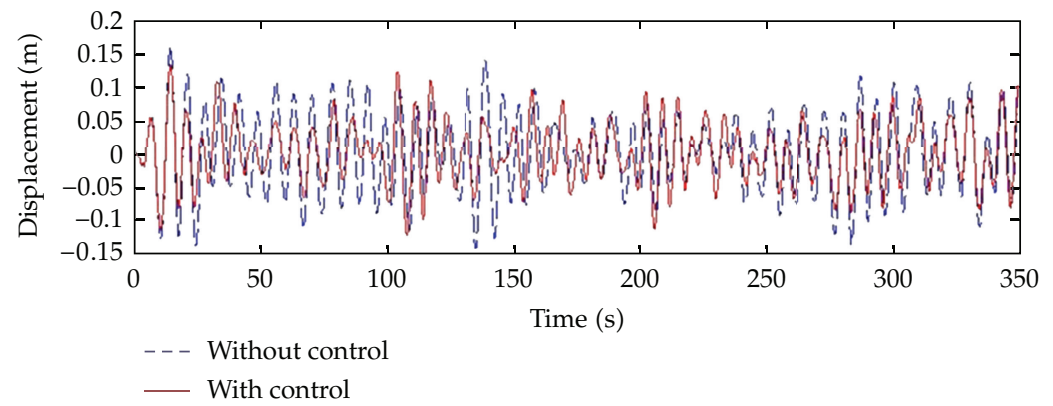

Figure 14: Displacement time histories with and without TLD control on top story of structure.

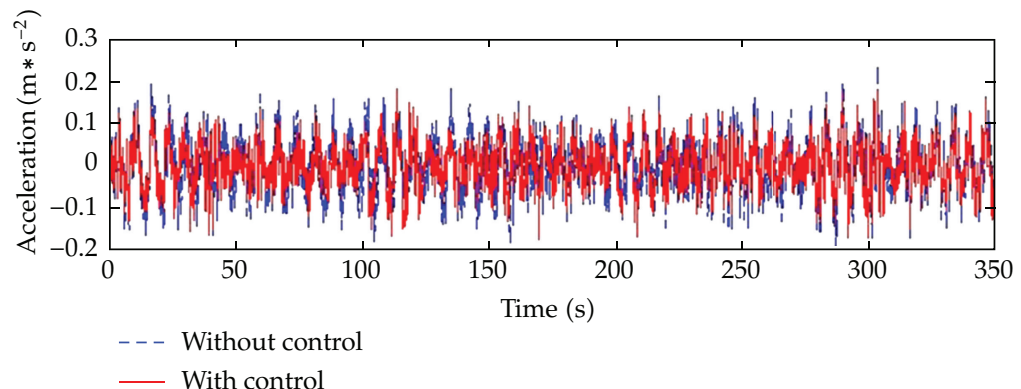

Figure 15: Acceleration time history with and without TLD control on top story of structure.

liquid density, $\ddot{x}_{T}(t)$ denotes the story acceleration where TLD is located, and $b_{n}=4 R / n^{2} \pi^{2}$ and $\ddot{\omega}_{n}(t)$ means the acceleration of liquid motion in TLDs.

It is known from the previous section that the first modal response is dominant in the wind-induced vibration of high-rise structures. Therefore, controlling the first modal response is normally enough by TLDs. Thus, the equation of liquid motion in TLD is expressed as follows:

$$
\ddot{\omega}_{1}(t)+2 \tilde{\zeta}_{1} \tilde{\omega}_{1} \dot{\omega}_{1}(t)+\tilde{\omega}_{1}^{2} \omega_{1}(t)=-\ddot{x}_{T}(t)
$$

and by taking $\tilde{\zeta}_{1}=0.08$ and adjusting $\tilde{\omega}_{1}$ to first mode frequency of structure, (5.3) is rewritten as

$$
F_{\mathrm{TLD}}=-M_{T}\left[\ddot{x}_{T}(t)+a_{1} f_{1} \ddot{\omega}_{1}(t)\right]
$$

where $M_{T}=\rho R B H, f_{1}=(R / \pi H) \tanh (\pi(H / R))$, and $a_{1}=8 / \pi^{2}$.

According to the tuning relation between frequencies of the TLD and structure, the design sizes of deep liquid TLDs are listed in Table 4, in which the liquid mass is the same as shallow liquid.

The reduced displacement and acceleration amplitude on the top of structure by installing deep liquid TLD are shown in Table 5.

Comparisons of vibration-reducing rates with two kinds of design plans of both deep and shallow liquid theories are summarized in Table 6. 
Table 4: Design sizes of deep liquid TLDs.

\begin{tabular}{lllll}
\hline Length/R Width/B & Liquid depth/H & Net weight of liquid $/ M_{T}$ & Mass ratio/ $\mu$ & Number of TLDs $/ n$ \\
\hline
\end{tabular}

\begin{tabular}{llllll}
\hline $9.95 \mathrm{~m}$ & $6.61 \mathrm{~m}$ & $3.98 \mathrm{~m}$ & $3666 \mathrm{t}$ & $1.0 \%$ & 14
\end{tabular}

Table 5: Vibration-reducing rates of displacement and peak acceleration.

\begin{tabular}{lcccc}
\hline Case & Displacement $/ \mathrm{cm}$ & Acceleration $/ \mathrm{cm} \cdot \mathrm{s}^{-2}$ & \multicolumn{2}{c}{ Vibration reducing rate $(\%)$} \\
Displacement & Acceleration \\
\hline Without control & 16.00 & 24.09 & & 19.01 \\
With control & 15.11 & 19.51 & 5.5 & 19.01 \\
\hline
\end{tabular}

Table 6: Comparisons of vibration-reducing rates of two design plans.

\begin{tabular}{lcc}
\hline Plan & Reducing rate of peak displacement $(\%)$ & Reducing rate of peak acceleration $(\%)$ \\
\hline Deep liquid & 5.5 & 19.01 \\
Shallow liquid & 17.06 & 23.85 \\
\hline
\end{tabular}

It is clearly seen from Table 6 that the designed shallow tank has higher efficiency than deep one for both displacement and acceleration. Especially, it makes the vibrationreducing rates of displacement increase nearly $12 \%$ and $5 \%$ for acceleration. Thereby, it is recommended to utilize the shallow liquid theory to design the TLD in practical projects because of its higher efficiency.

\section{Preliminary Design Procedure in Wind-Induced Vibration Control by TLDs}

A preliminary design procedure was summarized and outlined for specified target structural response amplitude corresponding to wind-induced serviceability level accelerations. The simple design procedure allows a designer to apply well-known TLD design theory to a TLD equipped with damping screens.

Step 1. After calculating the basic frequency of high-rise structure, the TLD frequency is adjusted to the structural frequency.

Step 2. Combining with the practical situation of engineering projects, the liquid tank sizes for TLDs are designed by the shallow liquid theory.

Step 3. The number of tanks is decided after determining liquid tank mass. Usually, the tank mass is taken as about $1 \%-5 \%$ of the total structural mass.

Step 4. The proper positions are selected to install liquid tanks (usually on equipment floors).

Step 5. The system of structure-tank interactions is calculated to obtain the structural responses by the shallow liquid theory.

Step 6 . The design should be going on by returning to Step 3 and adjusting the number of tanks until the required results are achieved if the control effectiveness is not as good as expected, otherwise the design work ends. 


\section{Conclusions}

The suppression of the significant oscillations of the high-rise buildings has become an important design consideration in recent years. It is, thus, necessary to find a cost-effective solution for suppressing the vibration. This paper gives a practical application for the effectiveness and feasibility of using the TLDs to the DITM, a super high-rise RC structure, to control wind-induced vibration. From both analytical and numerical inspections, some conclusions with practical significance can be drawn as the following.

(1) It is normally difficult to use the software of current structural analysis to do the 3D dynamic analysis because of more time consuming and more hard disk space needed. Thus, the FE model of original spatial structure should be simplified. On the other hand, the calculation model of the super high-rise building is generally a bending-shear one; that is, its rigidity matrix is full rank. The triple diagonal matrix simplified by traditional methods is not reasonable, while the identification method of equivalent rigidity coefficients is the better one. To facilitate design of the TLDs, the equivalent stiffness approach is adopted here to simplify the model. It has been known by numerical comparisons that two models were in good agreement with each other. Therefore, the simplified model can substitute the spatial FE model in structural dynamic analysis, which could save much more computing time.

(2) The harmonic synthetically method based on the trigonometric series superposition is used to simulate the pulse wind load for the DITM, and the FFT technique is adopted to make the calculation velocity faster. It has been proven by comparing the simulated wind velocity spectra with the on-site measured spectra that the approach adopted here is reliable and reasonable in the structural analysis.

(3) Comparisons between uncontrolled and controlled displacement and acceleration responses of the DITM under wind forces show that the designed shallow tank has higher efficiency than the deep one, which can effectively reduce the structural response amplitudes and enhance the comfortableness of the mansion. According to numerical results, the final designed TLDs on the top of structure suffered pulse wind load could efficiently make the reduction rates be as high as $17 \%$ for structural peak displacement and $23.8 \%$ for peak acceleration.

(4) The preliminary TLD design procedure summarized in this paper could be applied as a reference to the analysis and design of the wind-induced vibration for high-rise buildings using the TLD.

\section{Acknowledgments}

This research work was jointly supported by the Science Fund for Creative Research Groups of the National Natural Science Foundation of China (Grant no. 51121005), the National Natural Science Foundation of China (Grant no. 51178083), the Program for New Century Excellent Talents in University (Grant no. NCET-10-0287), the "111" Project (Grant no. B08014), and the Natural Science Foundation of Liaoning Province of China (Grant no. 201102030). 


\section{References}

[1] T. H. Yi, H. N. Li, and M. Gu, "A new method for optimal selection of sensor location on a high-rise building using simplified finite element model," Structural Engineering and Mechanics, vol. 37, no. 6, pp. 671-684, 2011.

[2] J. S. Love and M. J. Tait, "Nonlinear simulation of a tuned liquid damper with damping screens using a modal expansion technique," Journal of Fluids and Structures, vol. 26, no. 7-8, pp. 1058-1077, 2010.

[3] J. C. Wu, C. H. Chang, and Y. Y. Lin, "Optimal designs for non-uniform tuned liquid column dampers in horizontal motion," Journal of Sound and Vibration, vol. 326, no. 1-2, pp. 104-122, 2009.

[4] L. Huo, G. Song, H. Li, and K. Grigoriadis, "Hळ robust control design of active structural vibration suppression using an active mass damper," Smart Materials and Structures, vol. 17, no. 1, Article ID 015021, 2008.

[5] H. N. Li and X. L. Ni, "Optimization of non-uniformly distributed multiple tuned mass damper," Journal of Sound and Vibration, vol. 308, no. 1-2, pp. 80-97, 2007.

[6] H. N. Li, Y. Jia, and S. Y. Wang, "Theoretical and experimental studies on reduction for multi-modal seismic responses of high-rise structures by tuned liquid dampers," Journal of Vibration and Control, vol. 10, no. 7, pp. 1041-1056, 2004.

[7] M. J. Tait, "Modelling and preliminary design of a structure-TLD system," Engineering Structures, vol. 30, no. 10, pp. 2644-2655, 2008.

[8] K. M. Shum, Y. L. Xu, and W. H. Guo, "Wind-induced vibration control of long span cable-stayed bridges using multiple pressurized tuned liquid column dampers," Journal of Wind Engineering and Industrial Aerodynamics, vol. 96, no. 2, pp. 166-192, 2008.

[9] K. M. Shum, "Closed form optimal solution of a tuned liquid column damper for suppressing harmonic vibration of structures," Engineering Structures, vol. 31, no. 1, pp. 84-92, 2009.

[10] G. W. Housner, L. A. Bergman, T. K. Caughey et al., "Structural control: past, present, and future," Journal of Engineering Mechanics, vol. 123, no. 9, pp. 897-971, 1997.

[11] J. S. Love, M. J. Tait, and H. Toopchi-Nezhad, "A hybrid structural control system using a tuned liquid damper to reduce the wind induced motion of a base isolated structure," Engineering Structures, vol. 33, no. 3, pp. 738-746, 2011.

[12] H. F. Bauer, "Oscillations of immiscible liquids in a rectangular container: a new damper for excited structures," Journal of Sound and Vibration, vol. 93, no. 1, pp. 117-133, 1984.

[13] T. T. Soong and G. F. Dargush, Passive Energy Dissipation Systems in Structural Engineering, John Wiley \& Sons, New York, NY, USA, 1997.

[14] X. T. Zhang, R. C. Zhang, and Y. L. Xu, "Analysis on control of flow-induced vibration by tuned liquid damper with crossed tube-like containers," Journal of Wind Engineering and Industrial Aerodynamics, vol. 50, pp. 351-360, 1993.

[15] Y. Tamura, K. Fujii, T. Ohtsuki, T. Wakahara, and R. Kohsaka, "Effectiveness of tuned liquid dampers under wind excitation," Engineering Structures, vol. 17, no. 9, pp. 609-621, 1995.

[16] C. G. Koh, S. Mahatma, and C. M. Wang, "Reduction of structural vibrations by multiple-mode liquid dampers," Engineering Structures, vol. 17, no. 2, pp. 122-128, 1995.

[17] Y. Fujino, L. Sun, B. M. Pacheco, and P. Chaiseri, "Tuned liquid damper (TLD) for suppressing horizontal motion of structures," Journal of Engineering Mechanics, vol. 118, no. 10, pp. 2017-2030, 1992.

[18] K. Xu and T. Igusa, "Dynamic characteristics of multiple substructures with closely spaced frequencies," Earthquake Engineering and Structural Dynamics, vol. 21, no. 12, pp. 1059-1070, 1992.

[19] A. Samanta and P. Banerji, "Structural vibration control using modified tuned liquid dampers," Journal of The Institution of Engineers, Singapore, vol. 3, no. 1, pp. 14-27, 2010.

[20] T. Yi, H. Li, and M. Gu, "Determination and comparison of optimal placement scheme for dalian internatioanl trade mansion," Advanced Materials Research, vol. 243-249, pp. 5219-5222, 2011.

[21] H. C. Sun, N. S. Qu, and J. H. Lin, Computational Structural Dynamics for High Education, Dalian University of Technology Press, Dalian, China, 1992.

[22] X. T. Zhang, Calculations of Wind-Induced Pressure and Vibration for Structures, Publishers of Tongji University, Shanghai, China, 1985.

[23] Y. Li, H. Liao, and S. Qiang, "Simplifying the simulation of stochastic wind velocity fields for long cable-stayed bridges," Computers and Structures, vol. 82, no. 20-21, pp. 1591-1598, 2004. 
[24] X. T. Zhang, Calculation and Design Handbook of Engineering Resistant to Wind, China Architecture and Building Press, Beijing, China, 1998.

[25] H. N. Li, T. H. Yi, X. D. Yi, and G. X. Wang, "Measurement and analysis of wind-induced response of tall building based on GPS technology," Advances in Structural Engineering, vol. 10, no. 1, pp. 83-93, 2007.

[26] L. M. Sun, Y. Fujino, and K. Koga, "A model of tuned liquid damper for suppressing pitching motions of structures," Earthquake Engineering \& Structural Dynamics, vol. 24, no. 5, pp. 625-636, 1995. 


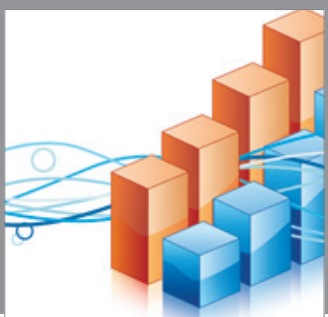

Advances in

Operations Research

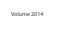

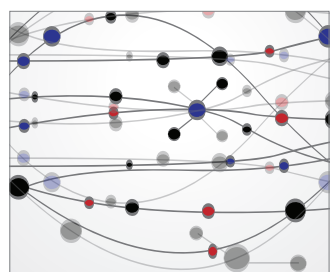

\section{The Scientific} World Journal
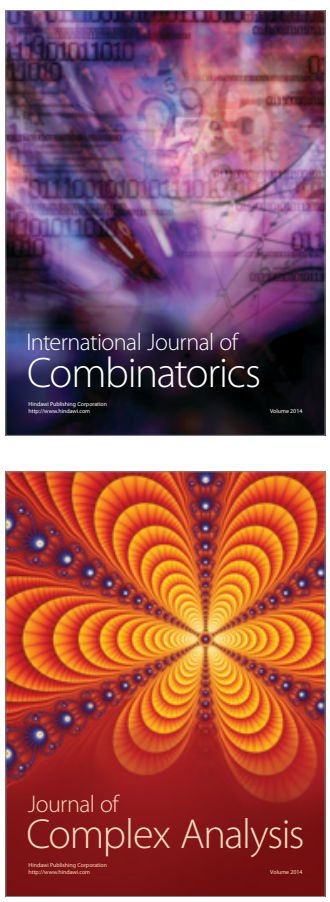

International Journal of

Mathematics and

Mathematical

Sciences
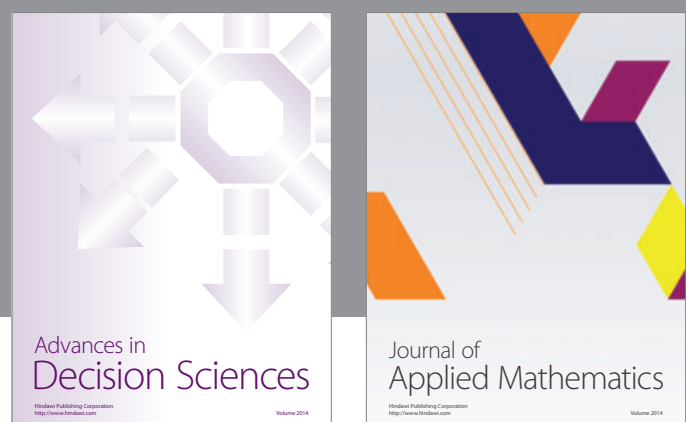

Journal of

Applied Mathematics
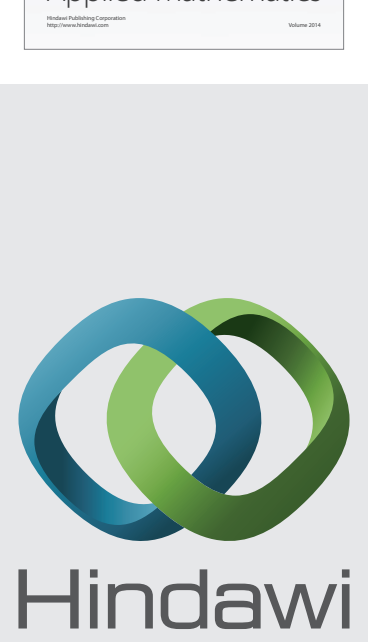

Submit your manuscripts at http://www.hindawi.com
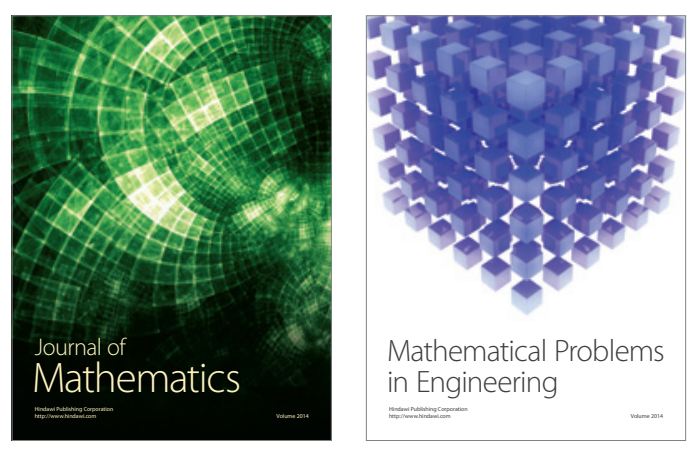

Mathematical Problems in Engineering
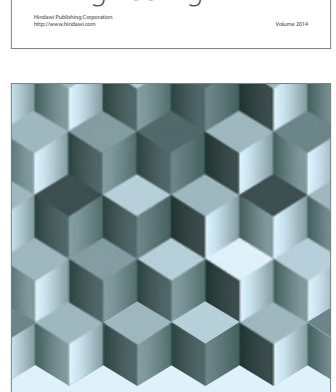

Journal of

Function Spaces
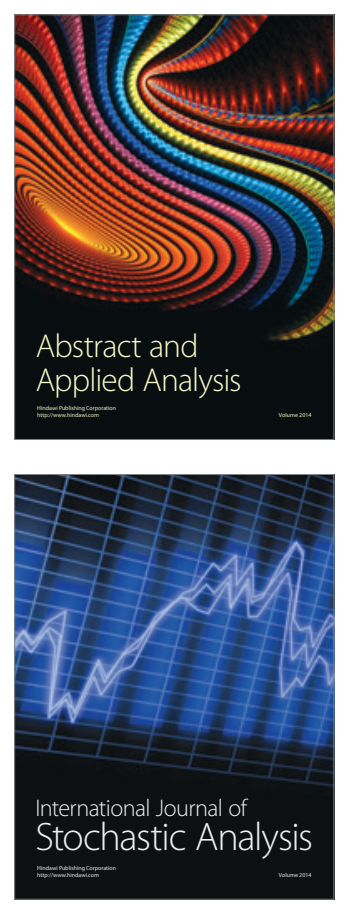

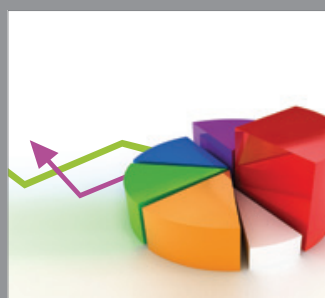

ournal of

Probability and Statistics

Promensencen
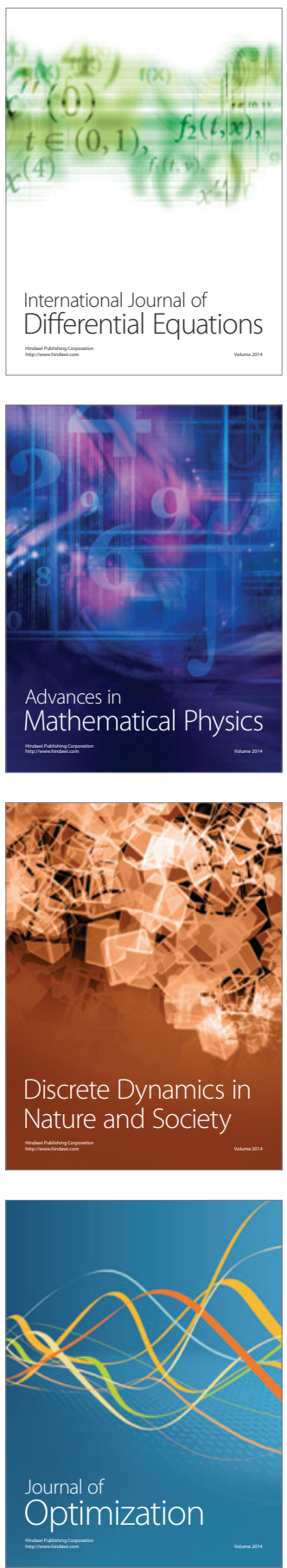